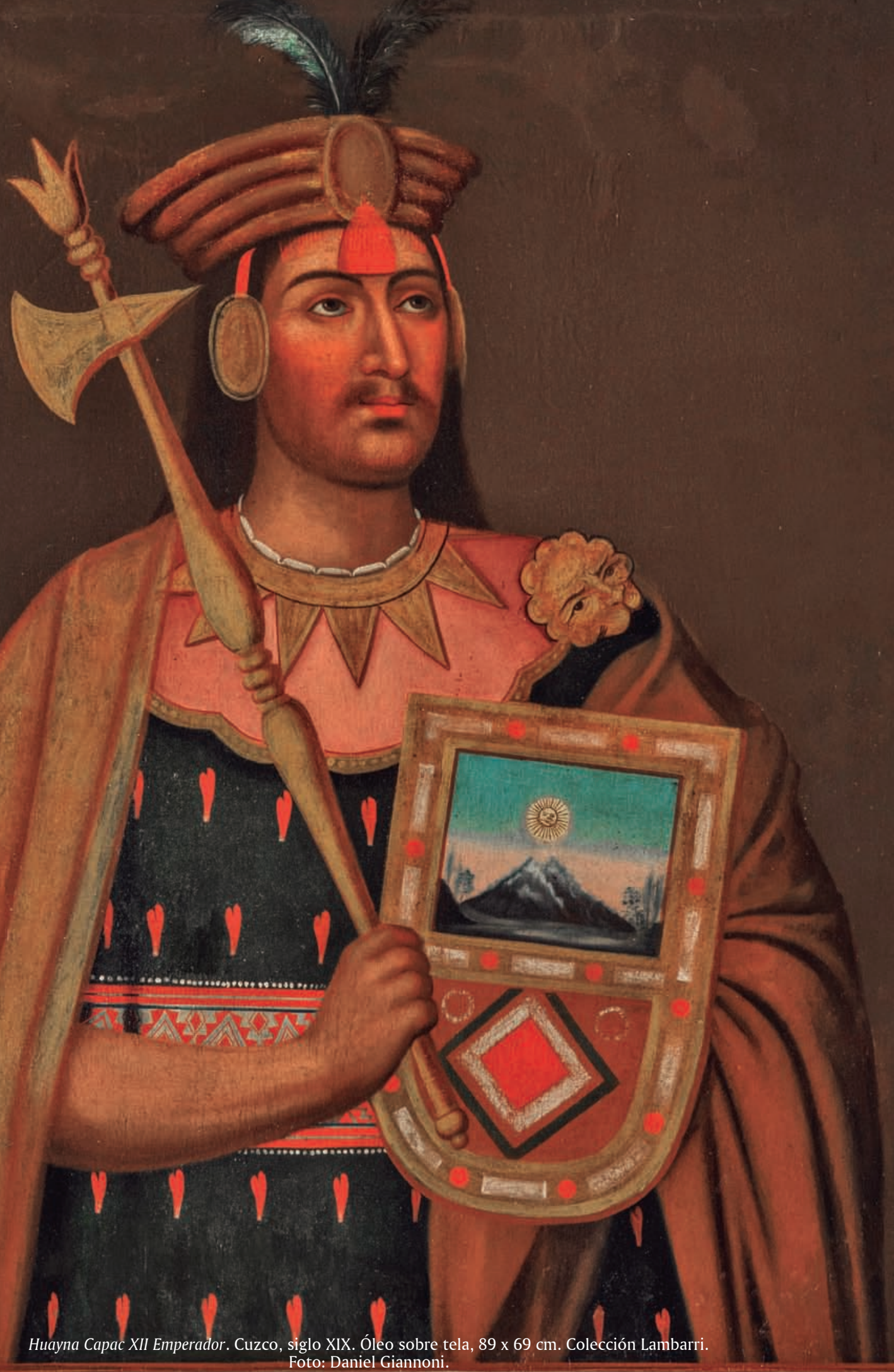
Foto: Daniel Giannoni.

Huayna Capac XII Enperador. fuè su gr Mamà-Rava-0cllo. 


\title{
Museología
}

\section{Arte del Sur Andino: la nueva sala del Museo Pedro de Osma}

\author{
Pedro Pablo Alayza \\ Museo Pedro de Osma, Perú \\ palayza@fundacionosma.org
}

Los sucesos que repercuten no son a menudo sino instantes, manifestaciones de estos grandes destinos,

y solo se explican por ellos.

(Fernand Braudel, 1969)

\section{Resumen}

La nueva sala del Museo Pedro de Osma, Arte del Sur Andino, Tiahuanaco, Inca, Virreinal-Siglos V al XIX, reúne una importante selección de obras precolombinas - perteneciente a la Colección Lambarri de Cusco- de estas culturas surandinas, además de obras virreinales. El objetivo de este nuevo espacio museográfico es confrontar estos universos culturales, a fin de mostrar al visitante de qué modo el arte virreinal cusqueño se sustentó en las creencias prehispánicas y cómo algunos elementos materiales de la cultura -el quero y el tupu- han seguido en uso bajo los mismos patrones ceremoniales desde el siglo $\mathrm{V}$ y durante el virreinato hasta fechas recientes. Se aplica así el concepto de la longue durée (la larga duración), que plantea la necesidad de enmarcar la historia de un territorio en procesos amplios, en lugar de considerar solamente la sucesión de acontecimientos.

Palabras clave: museografía, arqueología, colecciones, museos, sur andino.

\begin{abstract}
The new hall at the Museo Pedro de Osma (Pedro de Osma Museum), Art of the Southern Andean, Tiahuanaco, Inca, Viceroyalty - From the V to the XIX century, gathers an important selection of preColumbian works - belonging to the Lambarri Collection of Cusco - of these South Andean cultures, besides viceroyalty works. The objective of this new museographical space is to confront these cultural universes to show the visitor how Cuzco viceroyalty art was based on pre-Hispanic beliefs, and how some material elements of the culture -the quero and the tupu- have continued being used under the same ceremonial patterns, from the 5th century and during the viceroyalty until recent dates. The concept of the longue durée (long term) is thus applied, which raises the need to frame the history of a territory in broad processes, instead of considering only the succession of events.
\end{abstract}

Keywords: Museography, Archeology, Collections, Museums, South Andean.

\section{El contexto}

A lo largo de los años, la casa de verano de la familia de Pedro de Osma, en Barranco, ha sido un lugar destacado para el disfrute del arte virreinal en el Perú. Desde la primera mitad del siglo XX esta casa y su colección, a las que se sumaba la legendaria cordialidad de Pedro

1 "Les événements retentissants ne son souvent que des insțants, que des manifestations de ces larges destins et ne s'expliquent que par eux.” Braudel, F. (1969, p. 13). Écrits sur l'Histoire. París: Flamarion. 
de Osma, fueron distinguidas por ilustres visitantes. Esta casa-museo es sin duda un referente de la manera cómo se gestaron las colecciones privadas en nuestro país, además de ser un ejemplo de cómo el coleccionismo contribuyó a la conservación de un patrimonio que de otra manera se habría podido perder o dispersar a lo largo del tiempo.

Don Pedro de Osma, coleccionista y filántropo, guió personalmente a sus visitantes por los distintos ambientes hasta su muerte en 1967. Pasaron casi veinte años antes de que la casa y la colección fueran restauradas, durante los años 80. Al constituirse la Fundación Pedro y Angélica de Osma, los herederos consolidaron el deseo de los benefactores al dedicar su patrimonio, por un lado, a continuar las obras sociales y filantrópicas y, por el otro, a preservar el legado cultural en el sostenimiento del Museo Pedro de Osma. La tarea de restauración de la casa y la puesta en valor de la colección significaron un importante esfuerzo -en el que participó un equipo de destacados especialistas- que se consolidó con la apertura del museo al público en 1988.

En años recientes, el museo amplió su oferta a la comunidad mediante un intenso programa educativo y de mediación cultural, llevado adelante con gran profesionalismo, y que ha tenido muy buenos resultados tanto en la recepción de colegios privados y públicos de Lima como en el acercamiento a los vecinos barranquinos. Esto último tiene la intención de generar un vínculo más cercano con la comunidad local. Frente a estos resultados en la relación con el público -entendido como un actor importante para el crecimiento institucional-, los miembros del directorio de la fundación se plantearon nuevos retos para incrementar su captación. Entre otras estrategias, se propuso a la dirección del museo buscar una colección de arte precolombino. Las opciones, por cierto, eran múltiples, considerando las dimensiones del territorio, la gran riqueza del pasado y la diversidad de las culturas prehispánicas de los andes centrales.

\section{El concepto}

Al preguntarnos qué colección de obras precolombinas - de qué período o región- sería la más acertada para los fines del museo, entendimos que la propia Colección de Osma nos marcaba el derrotero, ya que está compuesta mayoritariamente por arte virreinal de origen cusqueño. A la luz de algunas notables pinturas, en las que la presencia inca es manifiesta, creímos que la mejor opción sería una colección de arte inca que ilustrara al visitante sobre la cultura de los antiguos señores de las tierras del sur andino, que precedieron el nuevo orden virreinal instaurado luego de la conquista española.

Gradualmente, la idea tomó forma. Logramos un acuerdo para trasladar a Lima una parte de la colección Lambarri, del Cusco -que cuenta con una notable selección de piezas Tiahuanaco, inca y virreinales que podría adaptarse a la propuesta de guion- y así otorgar una nueva perspectiva a la colección permanente del Museo Pedro de Osma. De este modo, la colección obtendría una profundidad temporal de más de mil años y un contexto geográfico que permitiría una mejor comprensión del contexto original en el que se gestó el arte virreinal, al tener como antecedentes artísticos y culturales las antiguas poblaciones surandinas. Además del planteamiento geográfico y temporal evidente en las colecciones señaladas, un tema que se presentó como indispensable fue proponer una historia común y la continuidad de la cultura andina entre los siglos V y XIX como recorrido único e irrepetible en un territorio determinado: el sur andino, entre los valles fértiles de los alrededores del Cusco y la gran llanura del Collao, alrededor del lago Titicaca. Este planteamiento parte de lo propuesto por la tesis de la longue durée, ${ }^{2}$ que expande la lectura de cada cultura,

2 La larga duración es un concepto acuñado en Francia por la Escuela de los Anales, que cuestionó la manera de estudiar la historia como una sucesión de acontecimientos e incorporó estos largos plazos para explicar la historia desde una perspectiva cultural más amplia. 
incorporando aspectos como la geografía y la economía, para entender el fenómeno cultural de un modo más complejo, lejos de una visión en el corto plazo, como se suele presentar en los museos tradicionales. Un ejemplo de museo en el que se ha aplicado la tesis de larga duración de Fernand Braudel es el MUCEM de Marsella, donde se da cuenta de la historia del Mediterráneo en su conjunto.

Bajo esta premisa, planteamos el uso de la sala de exposiciones temporales del museo $^{3}$ como el espacio que recibiría esta nueva colección y las pinturas cusqueñas del siglo XVIII del museo a las que hemos hecho referencia, particularmente el Matrimonio de la Ñusta, la Genealogía de los incas y Fiestas del Corpus Christi. Tomamos estas obras como base para establecer la relación entre el universo virreinal y el inca, en vista de la presencia manifiesta de la nobleza cusqueña. De este modo, se planteó un recorrido que siguiera el orden cronológico de las colecciones.

\section{El recorrido}

La nueva sala reúne una selección de piezas de las culturas Tiahuanaco e Inca, así como

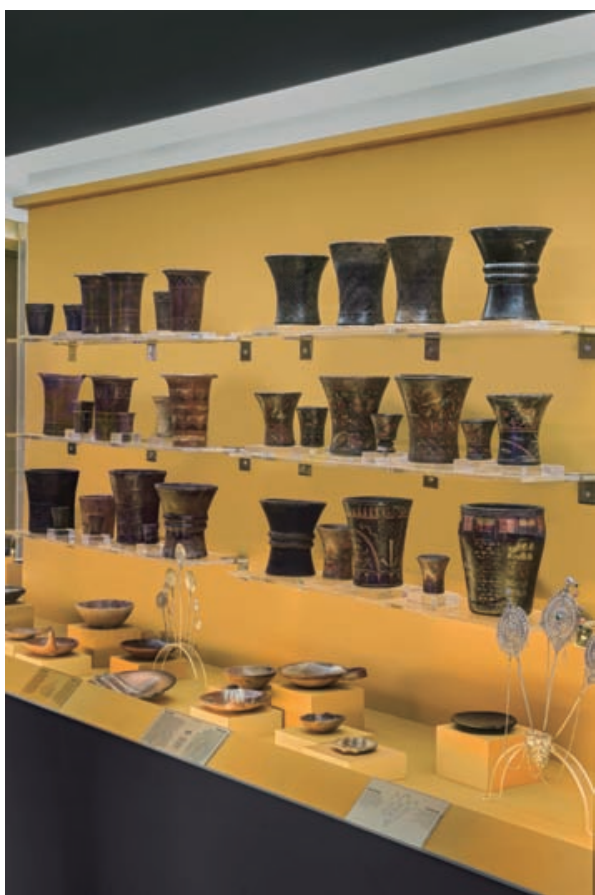

Vitrina Tiahuanaco.

Foto: Daniel Giannoni / Archivo Museo Pedro de Osma.

las pinturas virreinales de la colección del Museo Pedro de Osma. A manera de introducción del recorrido, así como al inicio de cada sección de la muestra, se ha incluido un texto que resume el espíritu de la propuesta: ${ }^{4}$

El sur andino fue el territorio donde se centró gran parte de la vida política de la historia peruana, desde períodos precolombinos hasta la época virreinal. Las piezas de esta exposición no solo nos permitirán profundizar en las prácticas locales, sino sobre todo aproximarnos al largo y complejo proceso artístico-cultural que se produjo en esta región.

Uno de los hilos conductores de la exposición es la permanencia del uso del quero como soporte y vehículo de la iconografía de cada momento relevante del sur andino. El origen de este vaso se remonta a las culturas más antiguas del altiplano y cobra particular fuerza durante el período Tiahuanaco. Resulta esencial considerar que el quero ${ }^{5}$ cumplió un rol destacado en los rituales andinos y fue adoptado por los incas. Posteriormente, mantuvo su vigencia durante el virreinato con una renovada iconografía polícroma. Su producción continuó en la República y su uso perdura hasta la actualidad.

3 La sala de exposiciones temporales del Museo Pedro de Osma se abrió al público en la década de los 90. En aquellos años esta sala fue uno de los escasos espacios de exhibición para el arte contemporáneo en el distrito de Barranco. A la fecha, han abierto varias galerías de arte y el Museo de Arte Contemporáneo, por lo que la trascendencia de este espacio para el museo ya había cumplido su ciclo.

4 Los fragmentos de textos introductorios corresponden al autor y forman parte de la museografía de la sala Arte del Sur Andino del Museo Pedro de Osma.

5 Cummins, T. (2004), así como Flores, J., Kuon, E. y Samanez., R. (1998), dan cuenta de la importancia del quero en el contexto ritual del sur andino desde tiempos anteriores a Tiahuanaco hasta el virreinato, e incluso más recientemente. 


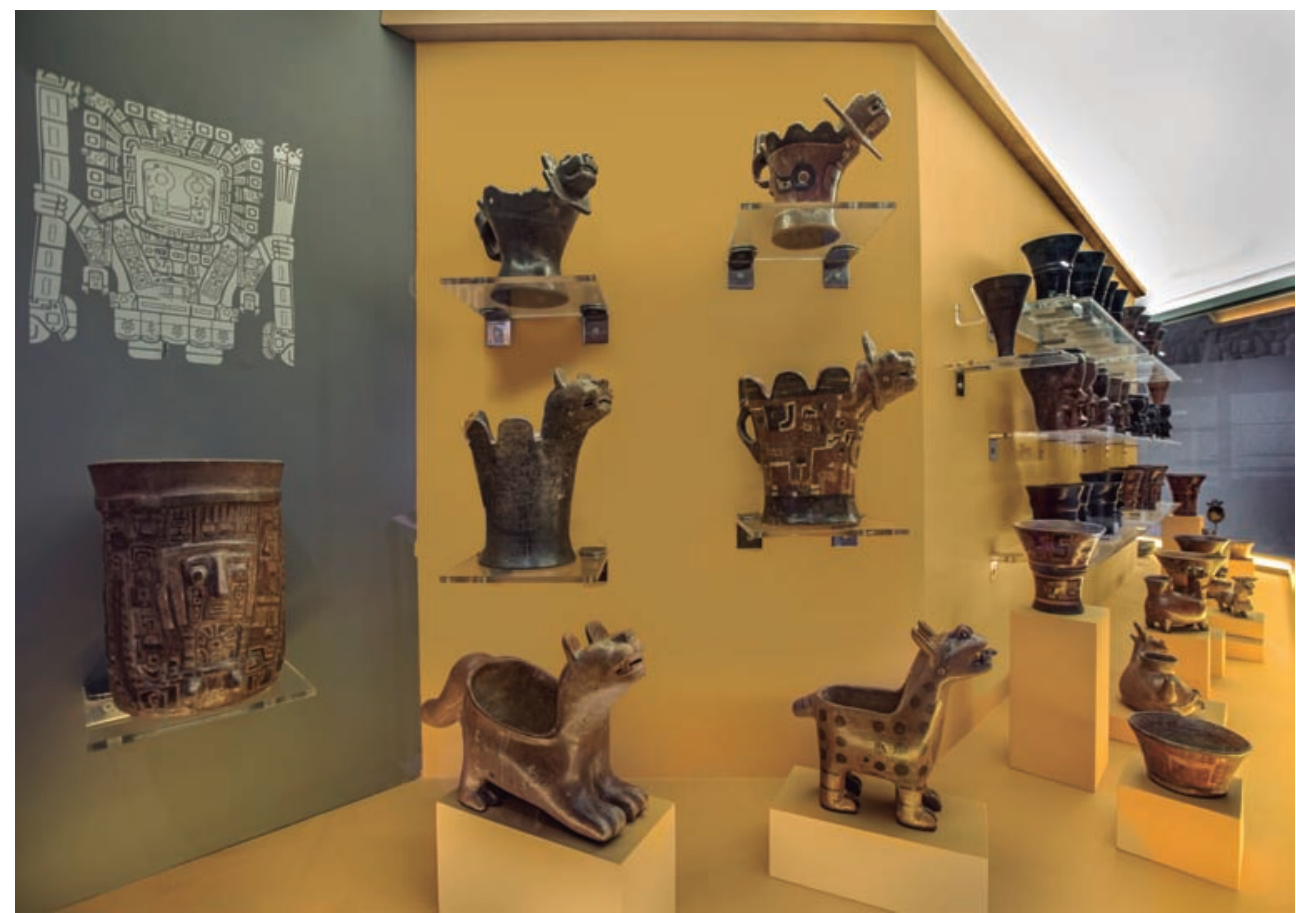

Vitrina Tiahuanaco.

Foto: Daniel Giannoni / Archivo Museo Pedro de Osma.

En cada uno de los textos introductorios del período se pone énfasis en algunos aspectos relevantes de la economía, la peculiaridad de la geografía y temas relacionados al arte y a la cultura pertinentes. En el caso de la cultura Tiahuanaco, que abre la exhibición, se muestra un detalle de la Puerta del Sol como una pieza indispensable para entender su estética y el estilo marcado por una severa simetría, así como la recurrencia de la imagen del Dios de los Báculos en el arte,

(...) soportes de gran sofisticación, como el quero y los sahumadores, fueron esenciales para la transmisión de su ideología religiosa. (...)

La regularidad del horizonte altiplánico -tanto del lago como del extenso llano del Collao- y el rigor del clima influyeron en la sensibilidad y en los patrones estéticos Tiahuanaco. En general, su arte muestra un gusto marcado por la simetría y la regularidad. Las edificaciones del sitio epónimo de Tiahuanaco se ven reflejadas en distintas disciplinas artísticas, como la escultura, la cerámica y la textilería, caracterizadas por su gran rigurosidad en el diseño y pulcro acabado. Entre los motivos de representación más frecuentes destacan las grandes figuras del panteón andino tradicional: el felino, las aves, los camélidos, la serpiente y la deidad de los báculos. Esta última está presente en gran parte de las obras y manifestaciones artísticas, y se encuentra en su máxima expresión en la célebre Puerta del Sol, en el sitio de Tiahuanaco.

La exhibición abre con una vitrina en la que se muestra una bella selección de incensarios de gran tamaño. Estos recipientes, que servían para la quema de sustancias aromáticas en contextos rituales, destacan por el remate almenado y la cabeza de un felino en la parte superior. Más adelante, una amplia colección de las distintas variedades 


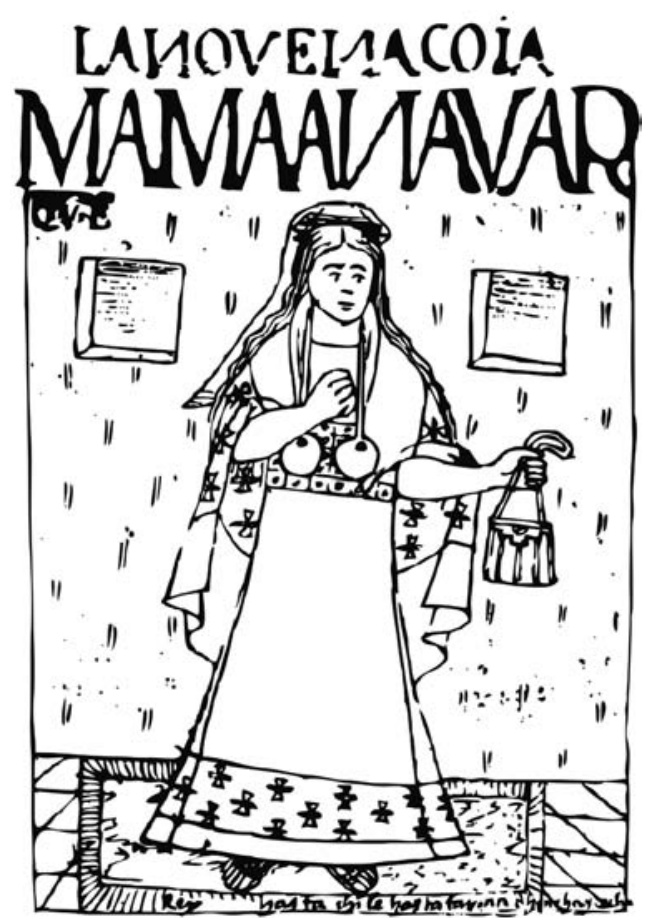

Felipe Guaman Poma de Ayala / Coya con atuendo característico y tupus.

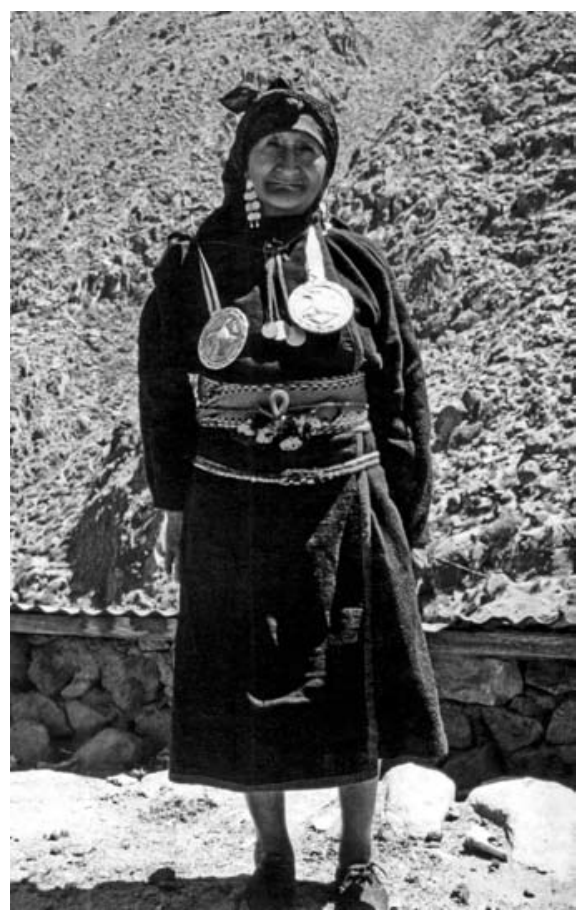

Mujer de Tupe (distrito de Yauyos, Lima) con vestimenta tradicional y tupus.

Foto: Luisa Vetter.

de queros de cerámica muestra las cuatro tipologías más comunes ${ }^{6}$ y las dos técnicas distintas de cocción, ${ }^{7}$ que se hacen evidentes en la coloración de las piezas, negras o rojizas. En la parte inferior de la vitrina se ha dispuesto un grupo de piezas escultóricas que dan cuenta de la destreza y sensibilidad del artista Tiahuanaco al representar la fauna local. Cierra esta vitrina un par de queros en bronce -llamados aquillas ${ }^{8}$ - y un grupo de tupus en plata con la característica punta roma que, en grandes líneas, los distinguen de los tupus inca. Estos últimos se encuentran en el espacio siguiente, acompañados por una imagen de Guamán Poma que ilustra el uso del tupu, así como por una fotografía de una habitante del pueblo de Tupe, en la sierra de Yauyos, que muestra la persistencia del uso de este objeto.

Siempre con la idea de señalar al visitante la importancia de la continuidad de los procesos culturales en el sur andino, se ha dado un espacio especial al mito de origen de los incas. En el relato recurrente en los dos mitos más conocidos -el de los hermanos Ayar y el de la salida de Manco Cápac y Mama Occllo del lago Titicaca-, los distintos héroes civilizadores recorren una ruta de sur a norte y llegan a los valles fértiles de Cusco, para fundar la dinastía que daría lugar al gran imperio del Tahuantinsuyo. Estos relatos han sido estudiados

6 Los cuatro tipos de queros mostrados son los que presentan anillos a distintas alturas del vaso, los huacos retrato, los que muestran el rostro del dios de los báculos y los queros challadores. Estos últimos se caracterizan por tener una base muy angosta, con orificio en la parte inferior para verter líquidos.

7 Los ceramios negros se obtienen evitando el ingreso del oxígeno al momento de la cocción (cocción reductiva). Las piezas rojizas son producto de la cocción oxidante, que permite el ingreso del oxígeno al momento de la quema.

8 La aquilla es el nombre que se da a los queros de metal, sean de bronce, plata u oro. Estos últimos estaban reservados para personalidades de alto rango. 
por destacados especialistas ${ }^{9}$ que sugieren que luego del colapso -ya sea por presión de grupos del sur o por otras razones- la élite Tiahuanaco sería el cimiento del futuro estado panandino. En opinión de Catherine Julien (2002), el mito de origen del Sol en el lago Titicaca y de sus hijos Manco Cápac y Mama Occllo fue utilizado por la élite inca políticamente; señala que "el culto de Titicaca fue ocupado y transformado para reflejar la unión entre la línea dinástica de los incas y ese importante ser sobrenatural" (p. 79).

La siguiente sección está dedicada a los incas:

Los incas supieron aprovechar el legado de las antiguas civilizaciones andinas como plataforma para su desarrollo y notable hegemonía: el bronce de los Tiahuanaco y la orfebrería norteña, así como la tecnología hidráulica y agrícola perfeccionada a lo largo de los siglos. Entre las piezas de arte que tenemos a la vista

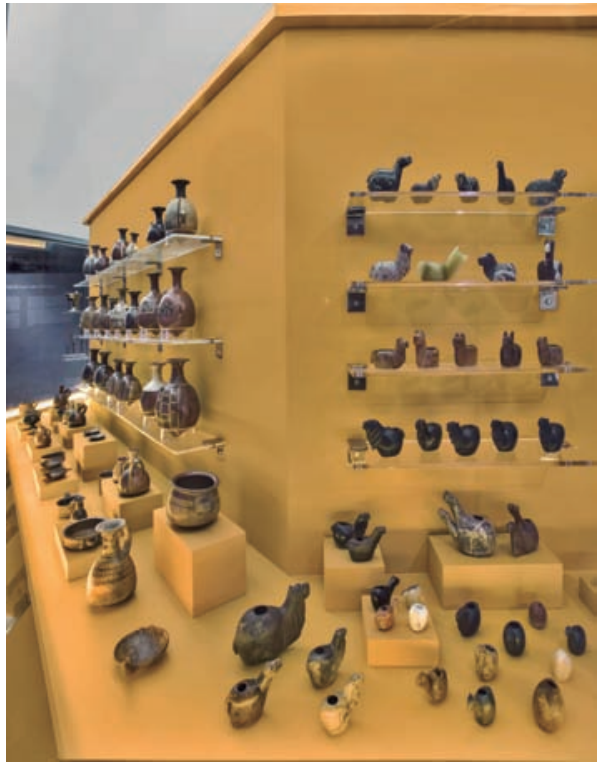

Vitrina Inca.

Foto: Daniel Giannoni / Archivo Museo Pedro de Osma.

destaca la gran colección de cerámica que reúne desde piezas de pequeño formato (como cuencos y platos) hasta los grandes aríbalos, y que nos da un panorama de casi la totalidad de los formatos y estilos de la tradición alfarera inca. Algunas formas

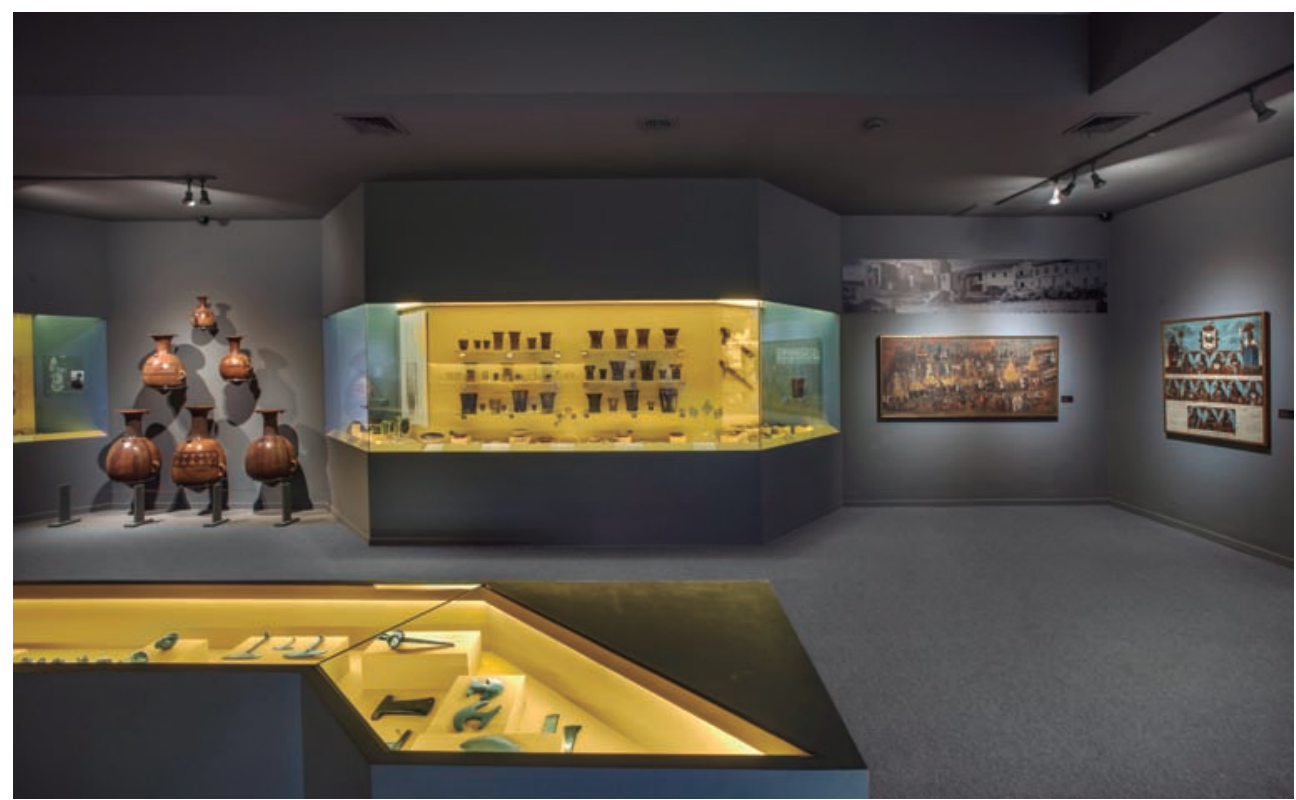

Vitrina Inca / Virreinal.

Foto: Daniel Giannoni / Archivo Museo Pedro de Osma.

9 Szemiñski, J. (2016), Espinoza Soriano, W. (1987). 


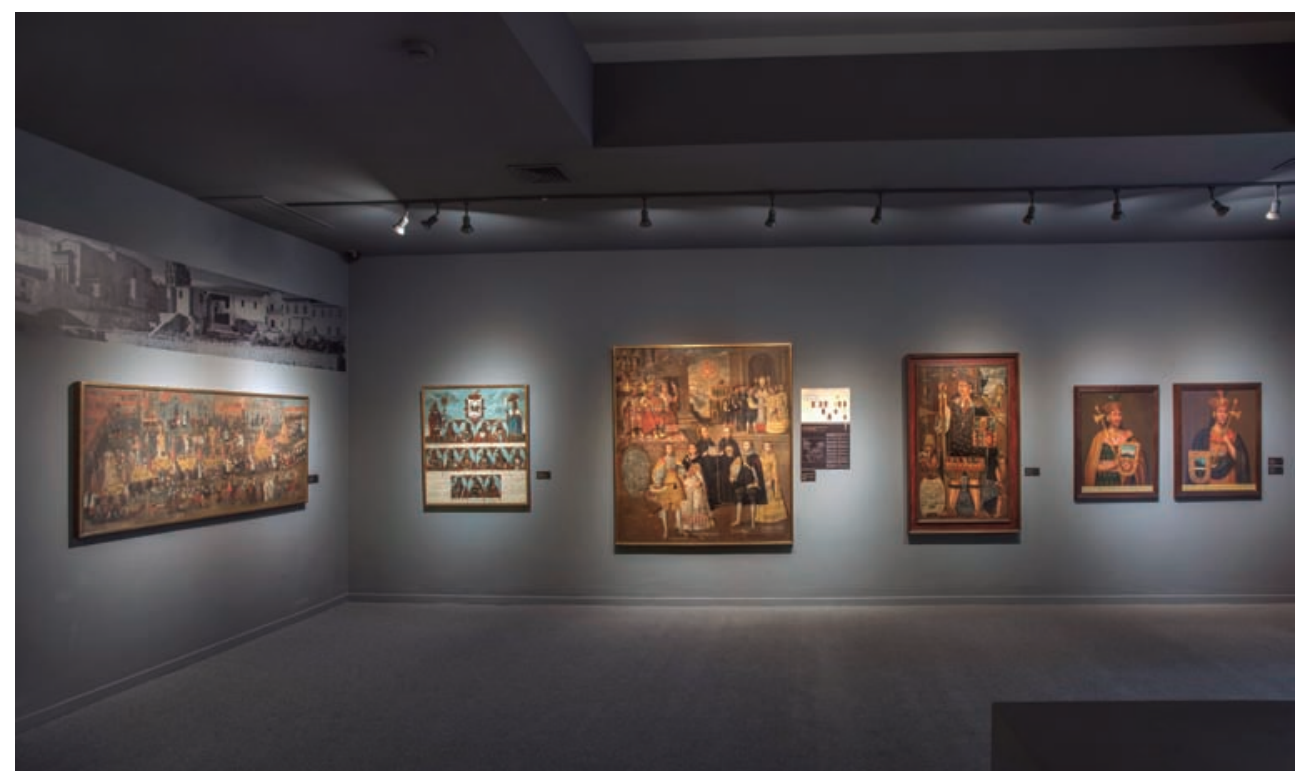

Presencia inca en la pintura virreinal.

Foto: Daniel Giannoni / Archivo Museo Pedro de Osma.

tradicionales, como el quero (muy difundido en el tiempo de los Tiahuanaco), se mantuvieron vigentes entre los inca, pero bajo los cánones estéticos propios de su cultura. Así, están marcados por un severo tratamiento geométrico tanto en madera y metal como en arcilla. Igualmente, la notable colección de conopas inca muestra su rica variedad de diseños, formatos y materiales.

También es posible observar los tupus o alfileres, compuestos por una varilla puntiaguda y una cabeza decorativa, que servían para sostener y adornar la vestimenta femenina. (...) Los tupus, como los queros de antigua tradición andina, siguieron en uso durante el período virreinal y el republicano.

La última vitrina dedicada a los incas es compartida con el período virreinal. En ella se puede apreciar varios pares de queros inca en cerámica y madera con motivos geométricos, así como aquellos llamados de transición, período en que los vasos de madera son decorados con motivos figurativos y rica policromía. Del mismo modo, se muestran tupus de transición de diseño inca con motivos de origen europeo. Cierra esta parte de la exhibición una amplia selección de pequeños objetos en una gran mesa central en la que se puede apreciar elementos de uso decorativo, como miniaturas de personajes que sirvieron de ofrendas, además de armas como los liwi-liwi o boleadoras, y contundentes macanas en bronce y piedra.

Con la ruptura del dominio inca sobre el extenso territorio del Tahuantinsuyo se desencadenó un proceso en el que las distintas tradiciones locales y regionales se adaptaron progresivamente a los nuevos patrones culturales promovidos por la Corona española. Este cambio constante y acomodo cultural -que perdura hasta el día de hoy- es parte de un fenómeno más amplio de aculturación y sincretismo, dinámica inevitable en el encuentro de dos civilizaciones distintas. (...) La supervivencia de antiguas costumbres se refleja en la adaptación de algunos elementos, como el tupu y el quero. Este último contribuyó a perpetuar el hábito del brindis por pares y se convirtió en un vehículo para transmitir a las nuevas generaciones las antiguas glorias y tradiciones de sus antepasados, los incas (...). 


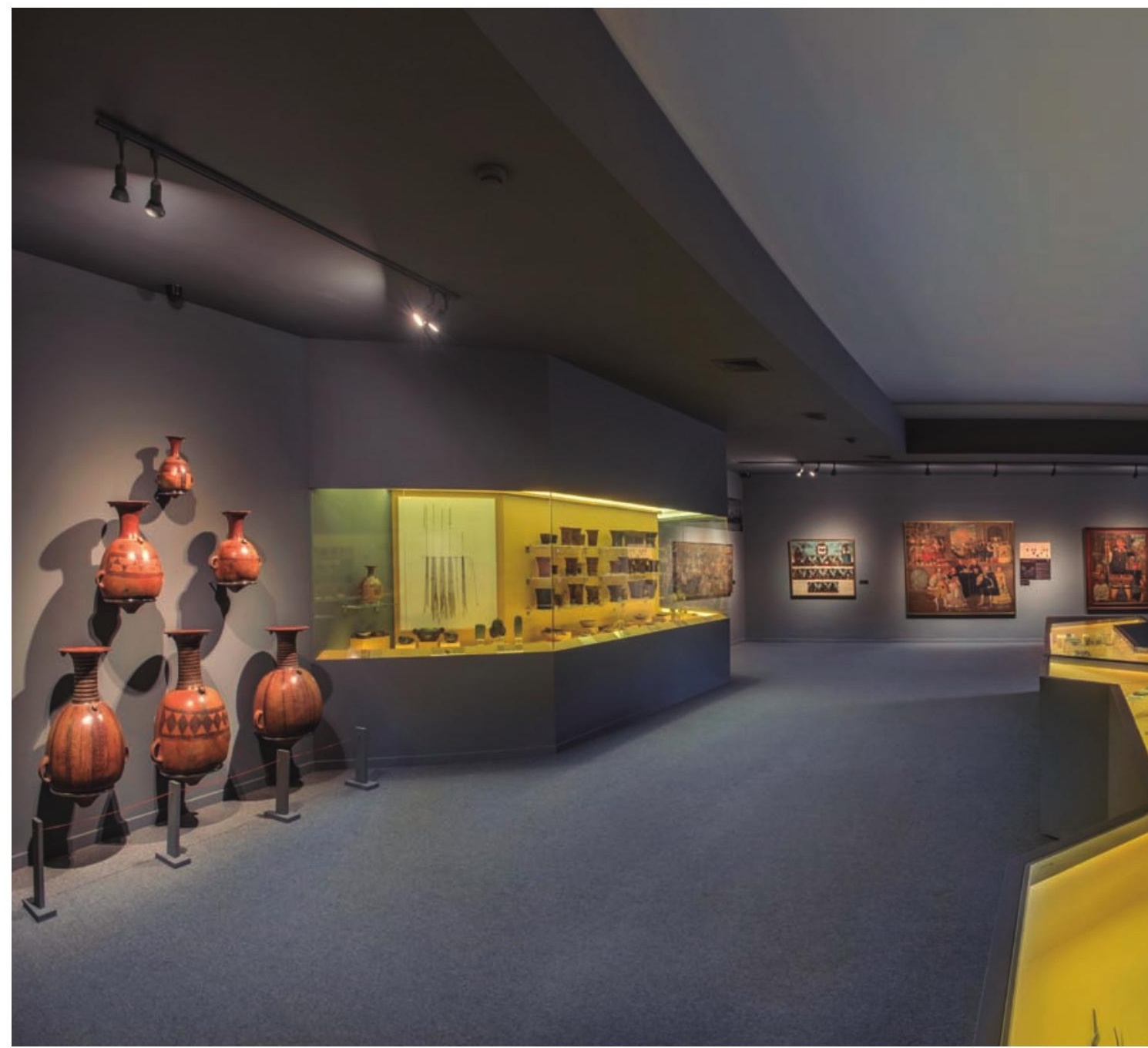

Vista panorámica de la sala.

Foto: Daniel Giannoni / Archivo Museo Pedro de Osma.

La élite inca, que durante el virreinato tuvo una posición de privilegio, continuó con diversos elementos que definieron parte de su identidad y jerarquía. Del mismo modo, en el ámbito de las festividades religiosas la población nativa preservó imágenes y prácticas de los cultos andinos bajo formas de devoción occidental. En esta sala ilustran este proceso los cuadros Unión de la descendencia imperial incaica con la Casa de Borja y Loyola y Procesión del Corpus Christi.

El recorrido concluye con los cuadros del museo señalados y con tres retratos de incas del siglo XIX, que ponen en evidencia la vigencia de estos temas en la época, como testigos de las antiguas glorias y de recuerdos irremediablemente perdidos en el tiempo.

La sala cierra con un panel educativo diseñado especialmente para facilitar la explicación de este complejo proceso cultural al público escolar y al visitante en busca de información puntual. En la parte central de este panel, una vitrina muestra grupos de queros Tiahuanaco, 


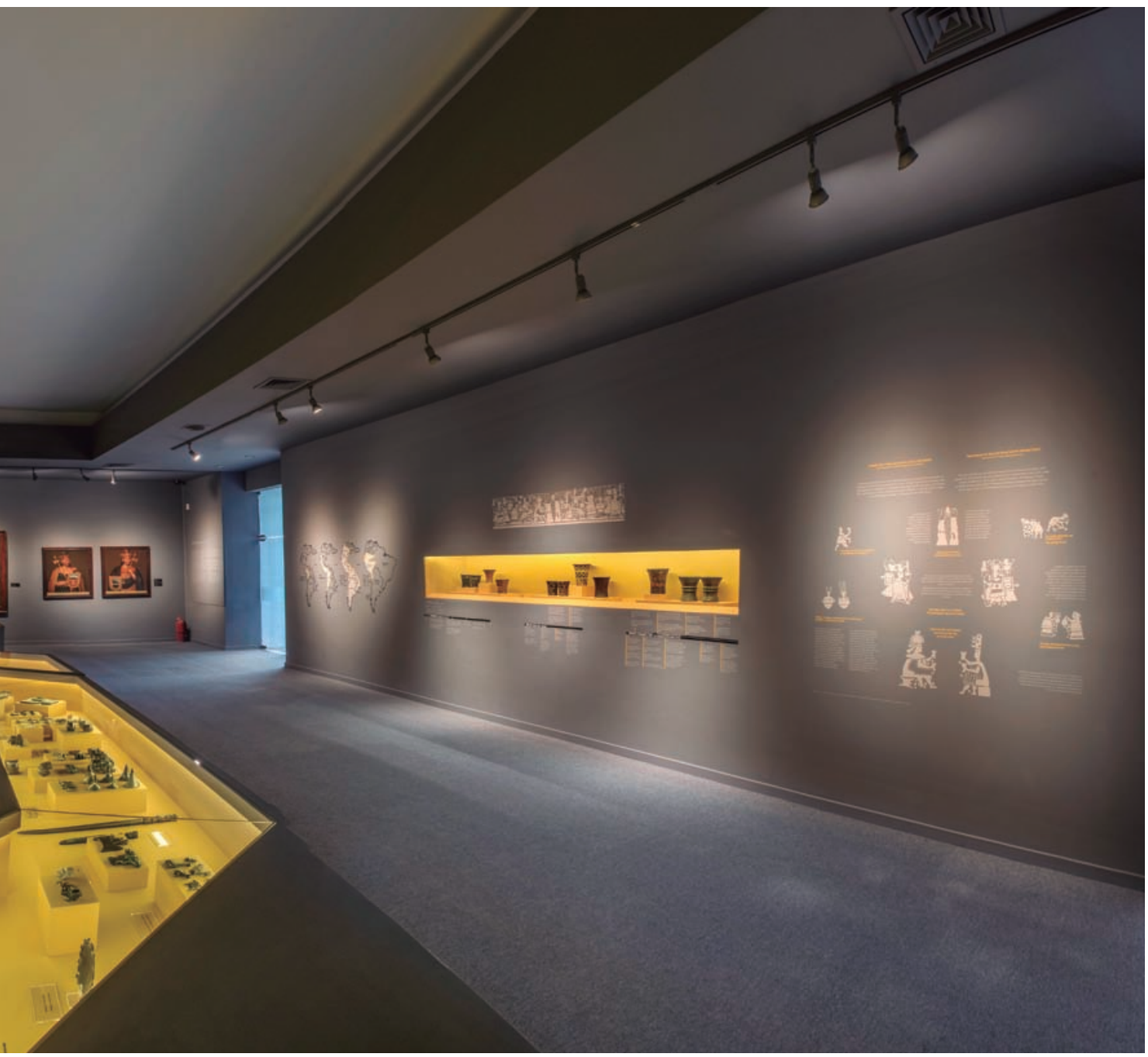

inca y virreinales ordenados cronológicamente, a fin de seguir la evolución formal del vaso ritual andino. Debajo de esta secuencia se ha colocado una línea de tiempo que detalla los acontecimientos y las características más relevantes de cada período. Finalmente, presenta como modelo un quero virreinal que ilustra un ritual de combate y brindis ente el Incari y el Collari, ${ }^{10}$ reyes Inca y Colla, respectivamente. La escena muestra a ambas autoridades con sus atavíos de guerreros, que luego del combate propiciatorio de la fertilidad -en el que, según se relata, el Inca siempre era el vencedor- se reunían en el punto de la divisoria de las aguas, entre los valles de Cusco y la cuenca del Titicaca, conocido como Vilcanota o La Raya, para brindar con un par de queros cada uno, reafirmando así la complementariedad de los dos territorios. Es interesante notar que este ritual se mantuvo vigente en

10 Descrito tanto por Cummins, T. (2004) como por Flores, J., Kuon, E. y Samanez, R. (1998). 


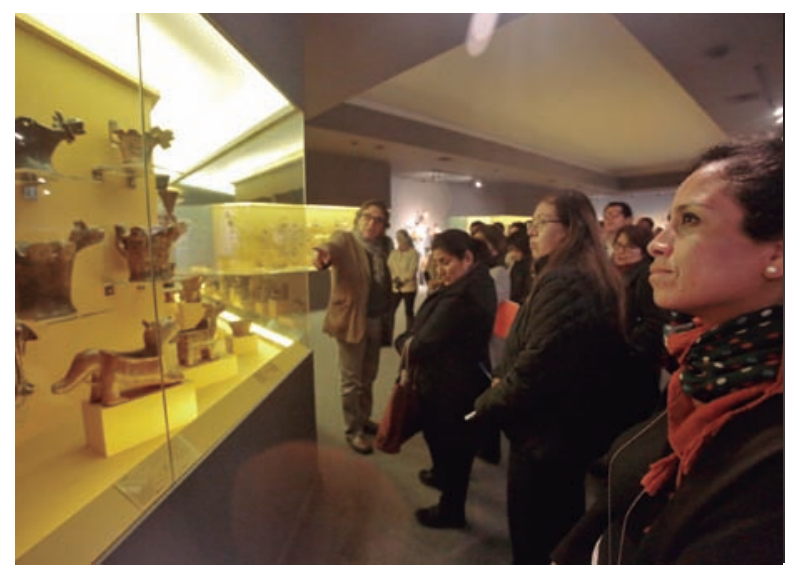

Visita guiada en la sala. Foto: Mayu Mohanna. la provincia de Canchis, al sur de Cusco, hasta mediados del siglo $\mathrm{XX}$; esto nos muestra la persistencia de los vínculos entre las dos regiones en tiempos tan recientes. El panel termina con la ilustración de los distintos personajes del quero y la correspondiente explicación de su rol en la escena señalada.

\section{Conclusiones}

Esta nueva sala del Museo Pedro de Osma ha servido para renovar el interés de la comunidad en el museo y replantear la manera de ver el arte virreinal a la

luz de sus antecedentes precolombinos. La idea inicial de incluir una colección de arte prehispánico para incrementar la asistencia del público fue pronto rebasada por el interés señalado líneas arriba, al integrar distintos períodos en una sola historia que abarca más de 1500 años en la región del sur andino. Esto amplía notablemente la manera de abordar el pasado peruano. En efecto, al dejar de aislar cada período en compartimentos estancos y proporcionar al gran público una lectura más amplia de la historia de ese territorio se hace posible ofrecer nuevas perspectivas para la comprensión de la complejidad del virreinato peruano.

\section{Ficha técnica}

Curaduría/museografía/textos: Pedro Pablo Alayza

Cocuraduría: José Ignacio Lambarri

Coordinación museográfica: Patricia Mondoñedo

Conservación: María Luisa Horna/David Diestra

Asistentes de investigación: Javier Chuquiray/María Paula Flores

Educación y mediación: Clara María Rodríguez

Comunicaciones: Blas de la Jara

Edición y traducción de textos: Alessandra Pinasco

Diseño de sala: Camila Gálvez

Diseño gráfico: Juan Luis Gargurevich 


\section{Referencias bibliográficas}

Bauer, B. (1992). Avances en arqueología andina. Archivos de Historia Andina. Cusco, Perú: Centro de Estudios Regionales Andinos Bartolomé de las Casas.

Braudel, F. (1969). Écrits sur l'Histoire. París: Flamarion.

Cook, A. (1994). Wari y Tiwanaku: entre el estilo y la imagen. Lima: Fondo Editorial PUCP.

Cummins, T. (2004). Brindis con el Inca. La abstracción andina y las imágenes de los queros. Lima: Fondo Editorial UNMSM.

Espinoza Soriano, W. (1987) Los incas. Economía, sociedad y Estado en la era del Tawantinsuyo. Lima: Amaru Editores.

Flores, J., Kuon, E. y Samanez, R. (1998). Queros. Arte inka en vasos ceremoniales. Colección Arte y Tesoros del Perú. Lima: Banco de Crédito del Perú.

Graulich, M. (1991). "La Realeza Inca”. En: Los Incas y el antiguo Perú. 3000 años de Historia. Tomo 1. (pp. 394 - 409). Madrid: Sociedad Estatal Quinto Centenario.

Korpisaari, A. y Pärssinen, M. (Eds.). (2005). Pariti: isla, misterio y poder. El tesoro cerámico de la cultura Tiwanaku. La Paz: CIMA.

Julien, C. (2002). Los Incas. Historia. Cultura. Religión. (Trad. Blanco, R.). Madrid: Acento Editorial. (Original en alemán, 1998).

Mujica, E. (1991). "Pukara: Una sociedad compleja temprana en la cuenca norte del Titicaca”. En: Los Incas y el antiguo Perú. 3000 años de Historia. Tomo 1 (pp. 272297). Madrid: Sociedad Estatal Quinto Centenario.
Mujica, R., Duviols, P., Gisbert, T., Samanez, R. y García, M. (2002). El Barroco Peruano (Vol. 1). Colección Arte y Tesoros del Perú. Lima: Banco de Crédito del Perú.

Murra, J. V. (1975). Formaciones económicas y políticas del mundo andino. Lima: IEP.

Pimentel, V. (Ed.) (2013). Pérou - Les royaumes du Soleil et de la Lune. Montreal: 5 Continents Eds.

Posnansky, A. (1957). Tiahuanacu: The Cradle of American Man (Vol. 3). La Paz: Ministerio de Educación.

Protzen, J-P. y Nair, S. (2016). Las piedras de Tiahuanaco, arquitectura y construcción de un centro megalítico andino. Lima: Fondo Editorial PUCP.

Rowe, J. H. (1944). "Inca culture at the time of the Spanish Conquest". En Handbook of South American Indians (pp. 183-330). Washington: Smithsonian Institution.

Sabogal, J. (1988). El kero. Vaso de libaciones cusqueño de madera pintada. Lima: Instituto Nacional de Cultura.

Szemiñski, J. (2016). De las vidas del Inka Manqu Qhapaq. Arequipa: Ediciones del Lector.

Young-Sánchez, M. (2004). Tiwanaku: Ancestors of the Inca. Denver: University of Nebraska Press. 